\title{
Kant desde dentro
}

\author{
JOSÉ LUIS VILLACAÑAS BERLANGA \\ Universidad de Murcia
}

\begin{abstract}
RESUMEN. Destaca este artículo la consideración que el propio Ortega hizo de su evolución filosófica entre los años 1914 y 1924 como un esfuerzo por salir de la cárcel del criticismo. Sin duda, este juicio autobiográfico determina la posición de Meditaciones del Quijote como un fiel reflejo de su aproximación a la filosofía crítica, frente a las interpretaciones vigentes que hacen de la primera obra de Ortega una temprana recepción crítica de la fenomenología. Sin embargo, este ensayo apoya la idea de que la brecha por la que Ortega abandonó la filosofía de Kant ya estaba trazada en su obra de 1914 y tenía que ver con las relaciones - muy tempranamente definidas - entre vida y cultura.
\end{abstract}

\begin{abstract}
This article emphasizes what Ortega said about his own philosophical development between 1914 and 1924 , that it was an effort to emerge from the prison of critique. Undoubtedly, this autobiographical judgment determines the position of Meditations on Quixote as a faithful reflection of Ortega's approach to critical philosophy, as against the prevailing interpretations, according to which his early work is a critical reception of phenomenology. However, this essay supports the thesis that the gap through which Ortega abandoned Kant's philosophy had already been traced in his work of 1914, and had to do with the relationships - defined very early - between life and culture.
\end{abstract}

\section{Kant y la jirafa}

En uno de los pasajes de su escrito homenaje de 1924, dijo Ortega que por fin podía mirar la casa de la filosofía kantiana como el que va al jardín zoológico a ver la jirafa. Aunque la metáfora nos despierta dudas, apenas se podrá inventar otra relación más externa entre dos cosas que la sugerida por un paseante que cruza el jardín de animales enjaulados. Sin embargo, aunque dudosa, la metáfora era coherente y, en cierto modo, concierta con otras empleadas en el mismo texto del centenario. A fin y al cabo, Ortega había iniciado su homenaje de 1924 diciéndonos que la filosofía de Kant había sido su casa y su prisión. Al ofrecernos aquella metáfora, Ortega nos venía a decir que él había sido la jirafa del zoo y que por fin, fuera de la jaula, podía estudiar su propio pasado desde la distancia del que está más allá de las rejas. Dejándose llevar por esa construcción barroca de alegorías, Ortega 
decide no contarnos nada del tiempo en que podía hablar de Kant desde el interior mismo de su ser. Son bien sorprendentes, en este sentido, las diferencias del tratamiento que Ortega dio al caso Goethe. Indispuesto como estaba a celebrar su centenario en 1932, reclamó un Goethe desde dentro. Alegre de embarcarse en una revisión de su relación con Kant, Ortega sólo se atrevió a decir que Kant era un pasado, aunque uno sólo disponible para los que, en su momento, habían vivido de la sangre espiritual del maestro de Königsberg.

En cierto modo, Ortega se aproxima a los dos grandes autores alemanes desde una misma reflexión: la experiencia del tiempo histórico de la modernidad. Antes de que Koselleck hubiera puesto estos temas en circulación, aunque quizás basándose en sus mismos ancestros teóricos, Ortega habla del tiempo histórico como trascendental de la vida humana ${ }^{1}$. Al fin y al cabo, Droyssen está tras la antropología histórica de Koselleck, como Dilthey está detrás de la razón vital de Ortega. Lo decisivo ahora, sin embargo, reside en una experiencia del tiempo histórico diferente en cada caso. Respecto a Kant, Ortega lo sitúa en el pasado porque lo ha digerido y superado. Respecto a Goethe, sin embargo, afirma que su clasicismo era una ruptura con el presente, por aquel entonces ya en manos de los nazis. Nadie había digerido a Goethe, nadie lo había conservado. La continuidad histórica se había perdido justo respecto al autor de Fausto. Era muy lógico que Ortega no estuviera dispuesto a celebrar a Goethe en 1932. Esa celebración le parecía un acto de impostura. Nuestro filósofo no veía en su tiempo credencial alguna para legitimar esa celebración.

En 1932, decía Ortega que «lo más problemático de nuestra vida es precisamente su relación con el pasado» $(O C$, III, 395). En 1924, por el contrario, todavía se sentía Ortega vinculado orgánicamente con él. De ese vínculo orgánico brota toda su metafórica. Él había hecho la digestión de Kant y había renacido en un nuevo espíritu, así que podía presentarse ante todos diciendo algo desde el presente al presente. Aquella lenta digestión de Kant había durado diez años, pero a través de ese lento proceso, y sólo por él, estaba en condiciones de identificar lo que necesitaban los tiempos. La tesis era ésta: «Yo dudo mucho que quien no haya hecho cosa parecida [habitar el pensamiento kantiano y respirarlo, hacer de él la casa y la prisión] pueda ver con claridad el sentido de nuestro tiempo» (IV, 25). No estamos hablando, por tanto, de un tema lateral. Quien quiera saber el sentido de la digestión de

1 Para este tema, cf. mis trabajos «Conceptos políticos y responsabilidad política», Res Publica, 1, 1998; la «Introducción» a R. Koselleck, Histórica versus hermenéutica, Barcelona, Paidós, 1995; igualmente, «Historique versus hermeneutique, les raison d'un dialogue», Entretiens de Madrid, Universidad Complutense de Madrid, septiembre de 2002; por último el trabajo «Histórica, Historia de los Conceptos y Teoría social», en el I Congreso de Filosofía Política, Universidad de Alcalá de Henares, ahora editado en el núm. 11 de Res Publica. Finalmente, desarrollo estas ideas en «El Imposible Leviatán», en el Congreso de Nápoles sobre construcción de un léxico político europeo, febrero de 2003 , en prensa. 
Ortega, y de la asimilación del alimento Kant, tiene en ese pasaje una pista. Se trata de identificar el sentido o Tema de nuestro tiempo. Ortega se expresaba de esta manera en 1924 porque venía de publicar, justo un año antes, el texto con el que, tras el fracaso de la segunda singladura política - España invertebrada - se refugiaba de nuevo en la filosofía, como lo había hecho diez años antes, en 1914, cuando tras el fracaso de la primera - Vieja y Nueva Política - se introdujo por esa senda oscura de las Investigaciones Psicológicas.

\section{La mujer de Lot}

Estas cuestiones circunstanciales de fechas son relevantes para entender el sentido de la obra de Ortega en este tiempo. Cuando Ortega comienza su escrito de homenaje a Kant diciendo: «Durante diez años he vivido dentro del pensamiento kantiano», el intérprete - que se ha dejado persuadir por la autoridad de Marías y de Silver - tiende inmediatamente a pensar que se refiere a los años que van desde 1905 hasta 1914, desde su primer viaje a Alemania hasta las Meditaciones del Quijote, texto que una crítica inverosímil - la de P. S. Silver - ha considerado la superación de la fenomenología descriptiva en la fenomenología existencial ${ }^{2}$. Lo verde que estaba Ortega en fenomenología se puede apreciar todavía en esas Investigaciones Psicológicas de 1915. Que seguía verde en ella se puede juzgar por las lecciones de Argentina de 1916, que otra crítica inverosímil ha rotulado con el infundado título de Meditaciones de nuestro tiempo ${ }^{3}$. En 1916, Ortega no tenía conciencia de haber superado a Husserl, ni nada parecido. Tenía plena conciencia de haberse hecho con cierto arsenal filosófico durante sus tres viajes alemanes y de conocer bien Cohen y cierta filosofía alemana. Como dijo con toda claridad en su gran momento autobiográfico, en el § 4 del Prólogo para alemanes: «En 1913 escribí mi primer libro, titulado Meditaciones del Qui-

\footnotetext{
2 Cf. mi trabajo «Ortega y la lucha por la hegemonía espiritual».

3 En su edición del curso, J. L. Molinuevo dice: «En realidad esto es lo que desarrolla en los cursos y conferencias de los dos viajes: un análisis de los temas y problemas de nuestro tiempo. De tal modo que los dos cursos bien pudieran llevar el título común que pensaba darle al de 1928: "Introducción al presente". Creo que con esto, la relevancia del texto de 1923 y el giro de la filosofía de Ortega queda difuso. Quizás ésta sea la última consecuencia de la vieja tesis de Marías y de Silver que hacen de Ortega un filósofo de una pieza y desde el principio, tesis del todo anti-intuitiva». Cf. José Ortega y Gasset, Meditación de nuestro tiempo. Las conferencias de Buenos Aires de 1916 y 1928 , edición de José Luis Molinuevo, Madrid, FCE, 1996. Ortega dice en la primera conferencia: «Mas con todo esto que os digo no hago sino dilatar lo que es mi principal obligación y a la par mi gusto más cierto: hablaros de filosofía. Nada más grato en estos tiempos de luchas, en que parece reinar sobre la tierra el odio y ofrece el hierro al hierro su cruel fiesta de sangre, reunirse con otros hombres y hablar con ellos de las eternas cosas filosóficas» (op. cit., pp. 38-39). Es decir: Ortega no quiere hablar de la guerra, que es el presente, el «nuestro tiempo», sino de las cosas eternas. No estamos desde luego en una meditación sobre el presente. Es filosofía en el sentido más clásico.
} 
jote; en él se iba a ver cuál era la reacción de mi espontaneidad a lo recibido en Alemania, que era en lo esencial neokantismo, idealismo». Que Ortega se acuerde también de que esa fecha fue la de la Ideas de Husserl y la Ética de Scheler no cambia las cosas: Ortega en 1913 escribió un libro en el que puso en limpio sus reacciones ante el neokantismo (VIII, 43).

Así que Ortega no quiere decirnos que durante los diez años que van desde 1905 hasta 1914 ha vivido dentro del pensamiento de Kant. Si hubiera querido decir esto en 1924, habría dicho con más claridad: «Durante diez años viví dentro del pensamiento de Kant». En 1924 desea decirnos otra cosa bien diferente, y es que acaba de salir de la cárcel de Kant. De ahí el tiempo del verbo. «Durante diez años he vivido» significa que, contando desde ahora, remontándose diez años en el pasado, Ortega ha vivido dentro de la cárcel de Kant, alimentado por él. Hay un cierto anuncio de buena nueva en la frase de Ortega, una voluntad de dotar de relevancia a la fecha, quizás incluso un coqueteo kabalístico con las coincidencias. A los doscientos años de su nacimiento, él se había por fin librado de Kant. Pero, en realidad, la trascendencia residía en algo más genérico. Ortega sugiere que durante este tiempo ha vivido dentro de la cárcel del idealismo en general ${ }^{4}$. E incluso más: puesto que en Kant se resumen cuatro siglos de filosofía occidental, desde el Renacimiento a la actualidad (IV, 25), al dejar en el pasado al idealismo, Ortega deja atrás toda la tradición europea. Por eso, al abandonar la idea de la filosofía de Kant al vivir histórico ${ }^{5}$, Ortega encuentra el tiempo presente. De ahí que, en ese año de 1923, pudiera escribir El tema de nuestro tiempo.

De hecho, hay un paralelismo entre el texto de Kant, reflexiones de centenario y el Tema de nuestro tiempo. Ese paralelismo permitió a Ortega decir con legitimidad que su salida de la cárcel de Kant coincidía con el cumplimiento del centenario. 1923-1924 ${ }^{6}$ era el año de la superación, de la misma manera que 1913-1914 había sido el año de la apropiación de Kant, autor que domina señero en Meditaciones del Quijote ${ }^{7}$. El período que va entre estas fechas había sido el tiempo de la asimilación. Por lo demás, y bien mirado, hay una innegable continuidad entre Meditaciones del Quijote y el escrito sobre Kant $^{8}$. Y, sin embargo, Ortega no nos ha querido hablar de

${ }^{4}$ De manera consecuente, Ortega reconoce que los que no han superado a Kant son esos políticos idealistas en los que alguien podría ver su propio retrato de 1914. A pesar de todo, diga lo que diga la frase en 1924, la clave que nos interesa por el momento es el idealismo de los que no han superado a Kant.

5 Kant ahora «vive "históricamente"», es decir, en el pasado, «perfectamente localizada en el alveolo del tiempo europeo».

${ }^{6}$ Hay que recordar que el artículo Kant salió en los números de abril y mayo de la Revista de Occidente de 1924.

7 Cf., para estos temas, mi edición de Meditaciones del Quijote, en prensa, en la editorial Biblioteca Nueva (Madrid).

${ }^{8}$ Continuidad que se puede resumir muy pronto: Meditaciones aspiraban a una síntesis entre el alma alemana y el alma mediterránea. Ortega, que en Kant desarrolla la genealogía étnica de su primer libro, ya no puede hablar de esa síntesis. Kant es el alemán perfecto, pero, contra Nietzs- 
este tiempo en que Kant estaba todavía en su sangre, de este Kant desde dentro. A Fernando Vela le dijo: «Me importa ante todo el futuro, y en mis escritos he insultado siempre a la mujer de Lot, a la cual, entre paréntesis, tampoco le importaba el pasado» (IV, 386). Esto lo dijo en el prólogo a Goethe desde dentro. Era su forma de decir que no estaba en condiciones de improvisar una autobiografía intelectual. En 1932, Ortega veía un presente que ya había abandonado los ideales universales de Kant y todavía no había encontrado los individuos al estilo de Goethe. Es curioso que, cuando en 1934 se prestaba a poner un prólogo a la tercera edición alemana de El tema de nuestro tiempo, Ortega se atrevió a escribir esa historia de su formación filosófica. Era la prueba de que seguía concediendo centralidad biográfica al texto en el que se había liberado de Kant. Entonces tuvo que interrumpirla porque ya no quería tener aquellos lectores alemanes. De esta manera, por una razón u otra, Ortega siempre encontró una razón para mantenerse fiel al odio que había mostrado una vez a la mujer de Lot.

En todo caso, espero haber dado argumentos para colocar El tema de nuestro tiempo en el centro mismo del pensamiento de Ortega y para conectar con su texto la culminación de la aventura de superación del idealismo kantiano. Ese camino que va desde la asimilación de Cohen a la liberación de Kant (1913-1914/1923-1924) debería darnos el Ortega que vivió a Kant desde dentro. Poco tendría esto de meritorio si, en ese camino, no se nos indicara la manera de encontrar el camino hacia Goethe. Mostrarnos el proceso de asimilación y superación de Kant sería así la clave para comprender por qué la misma empresa estaba pendiente respecto a Goethe. En cierto modo, el tema de nuestro tiempo era pasar desde Kant a algo mejor que Goethe. La abrupta falta de soluciones de El tema de nuestro tiempo debe relacionarse, entonces, con el hecho de que Ortega no había planteado con claridad el problema: ofrecernos un Goethe en proceso de superación, desde dentro. Ése sería el camino del pensamiento de Ortega tras 1924 y hasta 1932. El grado de madurez de la filosofía de Ortega dependerá en cierto modo de lo profundo de esta lucha con Kant y con Goethe. En ella se alberga lo que Ortega tiene que decirnos. Y, sin embargo, de esa lucha interior con Kant, nada se nos dice. Ortega quiere mirar su filosofía como el paseante por el zoo, no al propio pasado, como habría hecho la mujer de Lot.

che, eso significa que es el miedoso perfecto. En verdad, ese carácter miedoso depende de la soledad radical de la experiencia metafísica del alemán. De ahí que tenga la experiencia fundamental del propio yo (cf. III, 32). Ahora bien, frente a la tesis de Meditaciones, que hacía del alma griega un alma especial, por completo ajena al hombre meridional, en Kant se defiende la tesis de que el alma griega es parte del alma mediterránea, propia del mundo exterior, de la corporeidad, de la dificultad para conocer el propio yo. «Cuando Sócrates propone a los griegos su gran imperativo "Conócete a ti mismo", pone al descubierto el secreto meridional» (III, 37). Con esto, el ideal clásico de los griegos, que en cierto modo han reproducido los mejores alemanes, como Goethe, queda eliminado. De esta manera, también queda eliminado el tono peyorativo con que Ortega habla de los meridionales en la obra de 1914. 


\section{En el principio fue el caos}

La clave de la alegoría de Ortega respecto a su relación con Kant reside en concentrarnos justo en la puerta de la prisión kantiana. Esa puerta tiene una cara desde dentro y una cara desde fuera. Ortega, en su artículo del centenario de 1924, se mueve en el umbral, en ese lugar simbólico, doble, misterioso, propio del que acaba de dar el paso. La puerta de la prisión kantiana, mirada desde dentro, dice que en el principio es el caos y el desorden ${ }^{9}$. En cierto modo, ésa es la verdadera traducción existencial de la cosa en sí. La filosofía de Kant no puede partir del ser - como en la Antigüedad y en la Edad Media - porque el ser es caos. Este principio es el más básico, más todavía que el axioma que reduce la filosofía al problema del conocimiento. Lo decisivo del idealismo reside en el juego de ambos elementos. Pues el orden y la confianza en lo real - su conocimiento - no es un fruto natural de nuestra relación con el mundo, que es inmediatamente caos, sino nuestra propia construcción.

Todo lo que se pueda decir acerca de la necesidad de la crítica deriva de este principio ${ }^{10}$. El filosofema de Ortega dice que, puesto que sabemos que el conocimiento es un proceso complejo de construcción, necesitamos controlar nuestra propia obra. Ese control permanente de nuestra propia obra es la crítica. Para Ortega, una construcción sometida a la crítica será siempre «precaria y sin firme equilibrio» (IV, 35). Pero un mundo sin construcción propia será algo todavía peor: un abismo desordenado y confuso, la catarata de un tiempo desordenado.

9 «El moderno parte de la desconfianza, de la suspicacia, porque - Kant tuvo la genialidad de confesarlo con todo rigor científico - el mundo es para él un Caos, un Desorden» (III, 29).

10 En cierto modo, Ortega es poco convincente en este pasaje sobre la crítica, que recupera los temas de Nietzsche y de Sombart sobre el héroe guerrero y el burgués. La contraposición entre la filosofía antigua y la moderna, en este sentido, es francamente superficial. «La filosofía antigua, fructificación de la confianza y la seguridad, nace del guerrero» (III, 31). «La filosofía moderna, producto de la suspicacia y la cautela, nace del burgués». Las ideas proceden de la cultura de la guerra de 1914, el horizonte alemán que Ortega difícilmente puede superar en 1924. Se trata de una adaptación de los temas de la guerra de 1914, con toda su carga anticapitalista y antiburguesa muy evidentes en el texto de Ortega. El burgués es el industrial, el abogado, el homo economicus. Hasta tal punto es así que Ortega vincula el capitalismo y la época de la crítica. «Las etapas del capitalismo han sido, a la par, estadio de la evolución criticista» (III, 31). Las tesis de Ortega son aquí cercanas a las de Weber, pero claramente dirigidas contra Weber. «No digo, pues, que la filosofía crítica sea un efecto del capitalismo, sino que ambas cosas son creaciones paralelas de un tipo humano donde la suspicacia predominas. Serían producciones del mismo ethos, unidas por una afinidad electiva radical. Sólo que esa dependencia común de un tipo de hombre no significa para Ortega un ethos como en Weber, sino «un fenómeno biológico: el tipo de hombre que lo ha creado». Aquí tenemos una vez más una interpretación de la genealogía de Nietzsche en clave biologicista, llena de problemas. Esa interpretación biologicista de la genealogía nietzscheana, tampoco se nos presenta exenta de ellos.

Cf. el inicio del punto III. Cf. III, 32. 
Frente a esta puerta última de Kant, que desde dentro del criticismo se ve como caos, Ortega va a trabajar para identificar aquel aspecto que esa misma puerta tiene ya desde fuera, para el visitante del zoo. Esa puerta es desde luego la que nos enfrenta al misterio del ser. Sus dos hojas son un sí y un no y lo que las une es, en cierto modo, una decisión. Al negarlo como caos, Kant pensó el ser como incognoscible. De ahí la centralidad de la cautela, de la construcción, de la crítica. Llegado a ese límite, Kant edifica celda adentro para alejarse de ese caos, para sepultarlo y ocultarlo en los idealizados productos ficcionales de la cultura. Se supone que Kant llegó a la puerta luminosa de su laberinto, pero retrocedió ante él, proyectando superficies de ilusiones ideales para impedir la zozobra del abismo que se abría a sus pies. Ortega ha citado al castizo Barbero de Sevilla para indicar que esa precaución es inútil. Eso que para el miedoso burgués Kant es un caos ante el que hay que vivir de forma cautelosa, para el intrépido y heroico Ortega, visitante de la jirafa en el zoo, es de nuevo un ser ante el que estar confiado.

\section{El idealismo como innovación evolutiva}

De esta premisa acerca del caos cósmico - que ya utilizara Kant en Historia natural y teoría del cielo - ${ }^{11}$ es consecuencia el idealismo. Puesto que el ser es un caos amenazante, la única experiencia confortable para el hombre es la de su propio yo ${ }^{12}$. Las cosas para él no serán las cosas mismas, siempre dominadas por su secreto irreductible y peligroso, sino las cosas mediadas a través del yo; esto es: la conciencia de las cosas. Lo primario será, por tanto, la conciencia para sí misma y, en su campo, el idealista miedoso se siente a gusto, en la seguridad del hogar, en tanto que acaricia sombras en la soledad, no cosas en su carnalidad. Para Ortega, no hay diferencia profunda entre el idealismo de Kant y la fenomenología: ambas son filosofías ancladas en la autoconciencia. Para el idealista, el objeto primario de la conciencia es la conciencia misma. Esta premisa idealista es vista por Ortega como una paradoja: «empieza por lo que es segundo y hace de ello lo propiamente primario» $(\mathrm{IV}, 34)^{13}$. El horror al objeto es en todo caso lo determinante. De nuevo tenemos la metáfora: el idealista vive encerrado en la cárcel del yo, «cual en una ciudad sitiada». Salir de la cárcel de Kant es salir de la prisión del idealismo y es salir de la celda del yo.

$"$ Cf., para un análisis de esta obra y del problema del caos, mi trabajo «Kant: Una razón consciente de su propio mito», El Mito. Teoría y Crítica, núm. 6, 1999, pp. 29-55.

${ }_{12}$ «Sólo existe para él con evidencia su propio yo; en torno a éste percibe a lo sumo un sordo rumor cósmico, como el del mar batiendo los acantilados de una isla» (III, 33).

${ }^{13}$ Conviene señalar aquí un error de la edición de 1924 en relación con la Obra Completa. En el cuaderno se dice "Como Tántalo encuentra cuanto toca permutado en oro...». Debía decir Midas, como es obvio. 
Ahora podemos comprender el destino trágico del idealismo. Define su vida como construcción y, para ello, impone un «soberano activismo» (IV, 44) ${ }^{14}$. Al mismo tiempo, asume que todos los materiales con los que construye son «conciencia de...». De ahí que todas sus construcciones son representaciones, ficciones. Su soledad es un trascendental insuperable, su compañía es el sueño de una compañía. Por mucho que exista la alteridad, será sólo una coloratura de la identidad básica del yo, su reflejo, su doble. Por mucho que exista el «fuera», será la «representación de fuera». La conciencia de la totalidad de las cosas con que adorna su cárcel el idealista no es sino su autoconciencia. El vínculo entre Kant y Husserl, vínculo consciente para Ortega, no es otro que Fichte (IV, 37). Así que Ortega, situado ante esta maraña de telones sobre los que el idealismo proyecta sus representaciones, en un acto de valerosa decisión, ha traspasado la densa película de las ilusiones y ha atravesado la puerta que hay en el fondo último de las mediaciones. Donde el idealismo pronunciaba un no, él ha dicho sí. Ha confiado en ese paso a la luz porque ha encontrado valor en un nuevo principio (IV, 39).

A Ortega le ha faltado decir que esa fórmula de la que procede su extraño valor es más bien mágica. En todo caso, él extrema la jovialidad de la nueva buena: «[El idealismo] ha llegado hasta el fin - ha llegado a descubrir que era un error - . Sin esa magnífica experiencia de error, una nueva filosofía sería imposible; pero, viceversa, la nueva filosofía - y la nueva vida - sólo puede tener un lema cuya fórmula negativa suene así: superación del idealismo» (IV, 39). Esa experiencia del idealismo ha sido descrita por Ortega como agotamiento. Él ha cifrado esta condición en la inmantenible adoración a la obra ya hecha, la cosificación de la cultura, que sepulta en la tumba de lo hecho el vértigo de lo que está por hacer. Antes de Adorno, quizás con Simmel, Ortega habló del fetiche sin vida de la cultura moderna idealista. Esa experiencia y esa adoración, propia de una compulsión repetitiva, en cierto modo convenía al hombre miedoso. El fetiche, en el fondo, no es sino un valor de sobreprotección añadido a un objeto por una mente cobarde. Su génesis está en la mentalidad que concede omnipotencia a las ideas. Nadie puede negar que el fetiche sea un procedimiento idealista. De hecho, fetiches son para Ortega, de manera consecuente, los ideales, que pretenden establecer un deber ser ante un ser que asusta, un deber ser estéril, imposible, ficcional, coartada para la agitación continua del activismo de un yo que jamás podrá ocultar la realidad luminosa del ser con el que un hombre bien dispuesto debería reconciliarse. Ese deber ser es la forma general con que el

\footnotetext{
${ }_{14} \mathrm{El}$ idealismo, de forma verosímil, sería una especie de paranoia de seguridad. Ese activismo es la energía compulsiva de alguien que exige y reclama orden, poder, control. Cf., para esto, John Farrell, Freud's Paranoid Quest. Psychoanalysis and Modern Suspicion, Nueva York, Un. P., 1996, especialmente pp. 28-41. Las consecuencias de Ortega insisten en una dimensión narcisista de toda la cultura idealista, que también es señalada por Farrell.
} 
idealismo dirige la actividad del yo reflexivo. La metacrítica de la razón pura es, por tanto, la razón práctica ${ }^{15}$. Frente a todo ello, parece que Ortega camina heroicamente hacia en encuentro con el principio de realidad.

\section{Vida}

Hoy sabemos de sobra qué ha encontrado Ortega cuando ha penetrado todos los velos de la cultura, cuando ha despojado de todos sus vestidos a Brunilda, cuando ha roto los muros de Jericó de la ciudad sitiada del idealismo. Hoy sabemos el sí que ha opuesto al no de Kant. El ser que no reclama cautelas, el ser que merece confianza, es la vida. Ella es la que nos ofrece «la gracia transeúnte» (IV, 43). Así que la confianza en la vida se recoge en el nuevo axioma: pensar es aceptar (IV, 45). Frente a esta aceptación de la vida, el deber ser idealista no es sino expresión de una voluntad reflexiva y aislada. De aquí surge la gran boutade del centenario de 1924. Kant anuncia la dictadura, una frase que en rigor no sabemos referir a la circunstancia española, pero que me inclino a asociar con la tesis del Ocaso de las revoluciones: la denuncia de toda voluntad de reforma, de todo ideal, ese «prurito reformista de lo real» ${ }^{16}$.

No encuentro la manera de entender esta salida de la cárcel de Kant sin un repudio de la voluntad idealista de aventura. Y no puedo dejar de vincular este tema con la ruptura de las tesis de Meditaciones del Quijote, justamente motivadas desde el espíritu de reforma y superación del alma mediterránea. Es muy curioso que la palabra que acude al final del texto de Kant sea la que determinó la interpretación idealista del Quijote en 1914, aquella que el espíritu alemán había elegido para exponer la aventura de nuestro hidalgo: Tathandlung. Ahora esta categoría no representa la empresa cultural profunda que el espíritu español debía asumir para forjar una síntesis clásica. Era más bien la palabra propia de una filosofía de vikingo. Creo que todo esto es coherente. La salida de la cárcel de Kant no era sino el esfuerzo de los diez años que van desde Meditaciones a las obra de 1923-1924: el Tema de nuestro tiempo y este largo artículo sobre Kant. Por eso, se puede leer el texto del centenario de Kant como una corrección de Meditaciones.

Lo decisivo del planteamiento de Ortega en Kant no reside en los discretos apuntes acerca de la nueva filosofía. Reside más bien en dos afirmacio-

\footnotetext{
15 Hace ahora veinte años, celebrando el centenario de la Crítica de la razón pura me atreví a ofrecer un artículo que se llamaba justo así: «La metacrítica de la crítica de la razón pura». Está editado en la Universidad de Salamanca, 1982. De esta manera, la teoría deja de ser contemplación para ser operación. Obviamente, aquella celebración del centenario, comparada con los textos de Ortega, daría para algún juego cabalístico.

${ }_{16}$ Aquí Ortega cita el Fichte de H. Heimsoeth, cf. III, 46: «tal vez el único libro bueno que hasta ahora existe sobre tan difícil filósofo», que fue publicado en 1923 y luego traducido en la Revista de Occidente a instancias de Ortega.
} 
nes. Primera, que la nueva filosofía no se puede alcanzar sino como negación de las afirmaciones del idealismo. Ortega citó a Hegel y con razón: la superación de Kant no es sino la negación de su negación. Segunda, que esta negación de las afirmaciones del idealismo sólo puede lograrse realmente desde dentro de las tesis de Kant. La llave para salir de la cárcel de Kant está dentro de su filosofía. En el fondo, la tesis de Ortega dice algo así: es preciso encontrar en el propio Kant los estímulos hacia su propia negación. Por eso, sólo se puede ir más allá de Kant a través de él. Sólo podemos vivir fuera de Kant reclamando uno desde dentro.

En realidad, este planteamiento, que era coherente con la memoria biográfica que Ortega había situado al principio de Kant, no había llegado a su plenitud en El tema de nuestro tiempo. Sin duda, allí ya había sugerido Ortega que el idealismo - que había profesado como filosofía propia - debía ser superado. Una nueva actitud debía emerger, una capaz de sintetizar la verdad con la vitalidad (III, 157). Por supuesto que la somera descripción del racionalismo en este libro de 1923 es convergente con las notas propuestas sobre Kant ${ }^{17}$. El tema de nuestro tiempo también denuncia el subjetivismo y el idealismo. Sin embargo, esta superación de Kant a través de Kant no está elevada a tema. Aquí todavía el problema se presenta como la necesidad de superar el dilema entre racionalismo y el irracionalismo. Negación es una palabra que sólo opera desde la exterioridad. Nada nos induce a creer en un lento proceso de maduración.

Quizás debamos analizar el problema de la dialéctica de la cultura y la vida tal y como lo había abordado Simmel, en plena convergencia con el neokantismo. Pues, para el joven Ortega, desde Meditaciones en adelante, e incluso antes, idealismo, neokantismo y cultura son la misma cosa. El pensamiento básico de Ortega no ha cambiado: la vida es la actividad o función inmanente al ser humano que, por su propia ley, aspira a trascenderse en productos culturales ${ }^{18}$. Ortega no confió nunca en Freud, pero esas funciones vitales implicadas en la producción cultural podía haberlas derivado de las pulsiones anímicas que descubriera el padre del psicoanálisis. Entonces podía haber defendido que aquellas pulsiones pueden relacionarse con bienes objetivos plurales. Además, este pensamiento era afín con la teoría weberiana de las esferas de acción. La vida encuentra satisfechas sus inclinaciones a través de determinados bienes -económicos, éticos, estéticos, epistemológicos, eróticos, religiosos - tal y como se conciben y atienden en esferas objetivas de acción social, como la economía, la institución política,

17 Cf. III, 161: «suspicacia, desdén hacia lo espontáneo, entusiasmo por la construcción, dependencia de los ideales, espíritu revolucionario, primacía del deber ser, afanes dictatoriales».

18 Literalmente: «La vida, decía Simmel, consiste precisamente en ser más que vida; en ella, lo inmanente es un trascender más allá de sí misma. Ahora podemos dar su exacta significación al vocablo "cultura". Esas funciones vitales - por tanto, hechos subjetivos, intraorgánicos-, que cumplen leyes objetivas, que en sí mismas llevan la condición de amoldarse a un régimen transvital, son la cultura» (III, 166). 
el arte, la ciencia, la religión o la familia. Cada una de estas esferas, sin embargo, está atravesada por un sentido de la razón y, así, compone diversas esferas de cultura. El kantismo, al descubrir en su análisis de la subjetividad cada una de estas formas específicas de la razón, fue la filosofía que podía inspirar estos planteamientos ${ }^{19}$.

Desde esta perspectiva, si los valores culturales de estas instituciones objetivas y racionales no se vinculan con aquellas pulsiones vitales, los productos culturales se quedan sin sentido, sin valor, aparecen como mera objetividad, productos rígidos sin vida que los sostenga. Pero si esos productos culturales, canalizados en su objetividad por la razón, entran en contacto con la vida, entonces se recrean en su sentido, se conectan con las fuentes mismas de la subjetividad humana y logran expresarse desde la vida misma, haciéndola consciente, fuerte, espontánea, confiada. Esa razón entraría en contacto con la vida y su autenticidad y creatividad serían un función de esa misma vida. De ahí que Ortega, en El tema de nuestro tiem$p o$, desplegando sencillamente la vieja tesis de la filosofía de la cultura - que ya poseía en 1914- llegara a un nuevo planeamiento. Con ello estuvo muy cerca de hallar el gran pensamiento de Weber: la escisión de las esferas de acción. Fue en el capítulo V de la citada obra y lleva por título «El doble imperativo». En su esencia no es sino una pormenorizada atención a la dialéctica que deben mantener las dos dimensiones de la cultura, la subjetiva y lo objetiva.

Esta dialéctica se resume en la tesis más bien moderadamente innovadora de que «la vida debe ser culta, pero la cultura tiene que ser vital» (III, 169). Igual de trivial es también la reducción de la noción de vida y, con ella, de la subjetividad, a biología. Pero atengámonos a la cuestión central. Ortega ha presentado esa tesis como si encerrara un doble imperativo: por un lado, la cultura ha de ser vital, creativa, genuina, auténtica, espontánea, confiada; por otro, la vida ha de ser cultura, espíritu, valor, objetividad, disciplina, regla racional. Si se recibe una cultura sin vida, tenemos utopismo cultural, misticismo, ficcionalismo sin fuerza, fetichismo sostenido por una general hipocresía. Si se vive sin aspiraciones culturales, entonces la vida se impone de manera indisciplinada, caótica, instintiva y caprichosa, incapaz de trascenderse y de superar el presentismo del instante. La cultura apropiada es aquella en la que un valor cultural roza de nuevo las energías vitales, excita la creatividad, produce fe y convicción.

Ortega aprendió muy pronto de Simmel que las relaciones entre la dimensión subjetiva y objetiva de la cultura están sometidas a una ley precisa e infalible. Esta ley quedó expresada por Simmel como tragedia de la

\footnotetext{
${ }^{19} \mathrm{He}$ desarrollado este aspecto en «Esferas de acción y sistema psíquico. Entre Freud y Weber», en Teresa Rocha Barco (ed.), Miscelánea Vienesa, Universidad de Extremadura, 1998, pp. 219-249, y «Esferas de acción y sistema filosófico. El carácter imprescindible de la metáfora», Daimon, núm. 24, septiembre-diciembre de 2001, pp. 111-127.
} 
cultura ${ }^{20}$, aunque Ortega habla con una ligera variación de «fracaso de la cultura» (III, 172). En sí misma, la ley bien podía proceder de Fichte. Dice sencillamente que los productos culturales, aunque originados en el yo, tienen una tendencia ontológica invencible a presentarse como no-yo. Se puede expresar esta ley de otra manera, que fue asumida por el joven Lukács: cuanto más refinamiento y perfección alcanza un producto cultural, tanto menos puede ser comprendido y recibido con vitalidad por sus receptores y tanto más condena al autor a su soledad ${ }^{21}$. Adorno asumió esta ley hasta el final, cargando con el elitismo del arte occidental. Ortega, por el contrario, ha deseado regular esta dialéctica y someterla a una ley. En esa esperanza ha cifrado su sentido el sociólogo del presente que a veces percibimos en Ortega. Así, aquellos dos imperativos pretenden impedir el fracaso de la cultura, regulando los dos elementos cuyo desajuste genera la tragedia. Así, en un esquema que se aproxima a una mínima teoría de las esferas de acción, Ortega nos propone la base de toda su antropología, que tiene desde luego un aspecto neokantiano, como se puede ver:

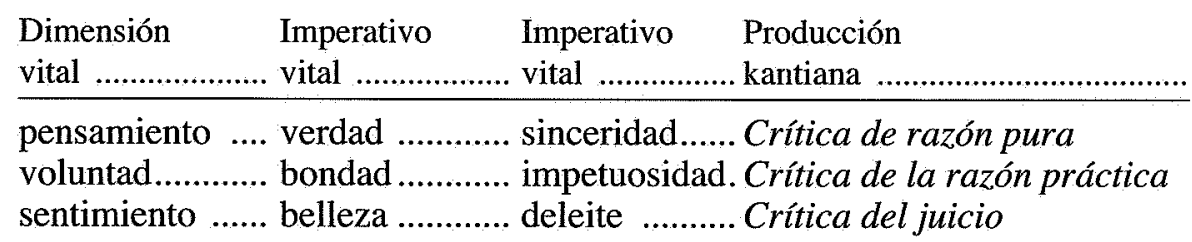

Así que la cultura, que ha promovido hasta ahora los imperativos culturales, deberá prestar más atención a los imperativos vitales. Como se puede suponer, esta síntesis equilibrada de ambos imperativos es la definición del clasicismo, tema que rondará a Ortega durante toda su vida y que será el asunto central de Un Goethe desde dentro. La superación de Kant implicaba todavía el reto de la verdadera asimilación de Goethe, como dijimos al principio. Ahora resultaba evidente que la evolución cultural de Europa daba síntomas precisos de objetivación y fetichismo, que era preciso compensar con los imperativos vitales. «Contra cultura, lealtad, espontaneidad, vitalidad», concluía Ortega en este capítulo central de El tema de nuestro tiempo (III, 173)

El planteamiento de Ortega surge del veredicto explícito de que Europa ha entrado en el peligro del objetivismo. El racionalismo es ese triunfo uni-

20 Simmel, Tragedia de la cultura y otros escritos, Barcelona, Península, 1982.

2t Ortega lo expresa así: «La cultura nace del fondo viviente del sujeto y es, como he dicho con deliberada reiteración, vida sensu stricto, espontaneidad, "subjetividad". Poco a poco la ciencia, la ética, el arte, la fe religiosa, la norma jurídica se van desprendiendo del sujeto y adquiriendo consistencia propia, valor independiente, prestigio, autoridad. Llega un momento en que la vida misma que crea todo eso se inclina ante ello, se rinde ante su obra y se pone a su servicio. La cultura se ha objetivizado, se ha contrapuesto a la subjetividad que la engendró» (III, 172-3). 
lateral del «polo objetivo de la vida: la razón» (III, 175). La afirmación del otro polo, del otro lado de la puerta, de la vida, se produce meramente al bucear en lo que, en todo caso, es necesario para la razón: las bases de la espontaneidad subjetiva y vital. La tesis alberga dimensiones de filosofía de la historia: si el mundo griego y el racionalismo occidental surgieron con Sócrates y se dispusieron a mirar con ironía la unilateralidad del polo vital, el mundo moderno ha llegado a su clímax con Don Juan, que mira con ironía la unilateralidad de la razón, conectando de nuevo al hombre con la vitalidad originaria (III, 177) y redescubriendo la espontaneidad. La obra de Don Juan debe ser acabada. No basta meramente mirar con ironía a la razón, sino someterla en verdad a la vida. Ésa es la misión del presente y el tema de nuestro tiempo (III, 178).

La vida libre de Ortega, como el juez infalible Dionisos, mira al racionalismo de Kant como a la jirafa en la jaula. Esa mirada se da antes de decidir qué hacer con la razón y cómo servirnos de ella para la vida. Todavía no sabemos qué hacer con ella, pero sabemos que ella no nos lo dirá. Si el idealismo había afirmado la Herrschaft der Vernunft, como dijo Fichte ${ }^{22}$, ahora el señor estaba encerrado y perdía su soberanía. En cierto modo, había pasado a ser un instrumento de la vida, que es la que tiene el cetro, «un principio y un derecho» (III, 179). Sin duda, Ortega ha señalado que su meta es «preparar una síntesis más franca y sólida» (III, 197). Como hemos dicho, resulta difícil identificar el momento en que Ortega va más allá de un clasicismo goethiano que tiene su máxima innovación en abrirse camino tras el caso excesivo de Nietzsche. Pues, en efecto, cuando intentamos identificar esta síntesis nueva, que Ortega duda en llamar «cultura biológica» o «razón vital» (III, 178), apenas llegamos a comprender su sentido y sus términos. Aquí los límites de la retórica de Ortega no nos ofrece un sentido de lo incomprensible, sino que nos hace más oscuro lo oscuro. Cuando Ortega habla, sencillamente, de «consagrar la vida», nosotros no sabemos qué quiere decir.

\section{El carisma de la vida}

En una de sus explicaciones, Ortega ha dicho que el intelecto, la ciencia, la moral, el arte y la justicia - lo que hemos llamado esferas de acción - «se supedita al organismo total del ser viviente y recibe de él su regla y su método» (III, 184). Ahora vemos una diferencia precisa entre la filosofía de la cultura y la filosofía de la razón vital: aquélla escinde las funciones vitales, se concentra en una unilateralidad vital, toma fragmentariamente la vida, exige una abstracción y la hace absoluta, infinita y utópica. Frente a esta escisión,

\footnotetext{
${ }^{22}$ Cf. el monográfico de Fichte que con este motivo y lema dedicó la revista Daimon (Murcia 1994), donde se reúne una buena colección de artículos de diferentes estudiosos de toda Europa.
} 
ante la que se rindió Max Weber, Ortega ha hablado del «organismo total del ser viviente» y repite que «esta divinización ilusoria de ciertas energías vitales a costa del resto, esa desintegración de lo que sólo puede existir junto - ciencia y respiración, moral y sexualidad, justicia y buen régimen endocrinotrae consigo los grandes fracasos orgánicos, los ingentes derrumbamientos. La vida impone a todas sus actividades un imperativo de integridad, y quien diga "sî" a una de ellas tiene que afirmarlas todas" (III, 186).

Sabemos ahora lo que ha querido defender Ortega. Él ha luchado por salir del neokantismo y, con profunda intuición, ha querido ofrecer una filosofía capaz de rechazar el diagnóstico weberiano: no dioses en lucha, sino dioses unánimes. La única manera de que la cultura no se cosifique en sus productos objetivos reside en que todos esos productos dejen de considerarse en la abstracción de su unilateralidad, para pasar a ser afirmados en su interpenetración a partir de la integridad vital. Sin duda alguna, Ortega cree que esto se lograría mediante la reconexión de las esferas de acción con el deseo y la vitalidad subjetivos (III, 187). Esto en realidad no se opondría a Weber ni a Freud. Pero, en realidad, la tesis de la integridad de la vida dice otra cosa. Ha de establecer que los deseos son coherentes, compatibles, orgánicos, funcionales entre sí. Esto, tras lo que sabemos de Weber y Freud, es algo que hay que argumentar con plena capacidad persuasiva.

Sin embargo, no está claro que Ortega haya abandonado el terreno de la mera declaración. Pero tampoco ha dejado de ver algunas cosas claras. En varios momentos nos habló del don, de la «gracia animal humana» (III, 190), de la bienaventuranza de la vida y en otro de ellos nos sugirió que todas las formas de vida posible son posibles (III, 189). En el fondo, Ortega aquí se dejó llevar demasiado fácil por el argumento de Nietzsche, para disciplinarlo luego a lo Goethe. Cuando se miran las cosas desde el punto de la jerarquía de lo alto y lo bajo, de la nobleza y la vileza, de la fuerza y la debilidad, entonces todos los grados de esta jerarquía se pueden organizar en una única escala y, en esta misma medida, todos son composibles. Pero sólo hay que pensar un poco para darnos cuenta de que, con ello, hemos traspasado la vieja metafísica de todos los grados posibles de perfección en la mente de Dios - que ya sirvió a Descartes para reintroducir la equivalencia entre la mente y el ser - al pensamiento de la vida que, así, nos permite aceptar el supuesto de la equivalencia del valor y la vida. Quizás sea demasiado pedir a Ortega que dispare contra la ingente metafísica de Nietzsche. Pero, sin ninguna duda, la erección de un criterio de valor inmanente a la vida reproduce demasiado fielmente el viejo esquema optimista de la teodicea ${ }^{23}$.

En el fondo, la mirada de Ortega sobre la vida no es suficientemente inmanente. Ortega ha proyectado sobre la vida un carisma que sólo haya valor en

${ }^{23}$ Por eso sería poco persuasivo para un weberiano, que ha desplazado toda teodicea a ética. Cf. mi trabajo sobre este tema en «Kant y Weber, o la disolución de la Teodicea en Ética», en Reflexión, vol. 3, Sevilla, 1999-2000, pp. 35-63. 
ella en la medida en que se afirma de manera total, íntegra, tendencialmente capaz de acumular sobre sí misma todos los grados de perfección, de reunir todas las unilateralidades en un organismo sintético de todas las esferas de acción en su interconexión, en su influjo recíproco, en su capacidad de influirse y regenerarse. En este proyecto, Ortega todavía deberá pensar cuando reclame un Goethe desde dentro. Pero, de entrada, imaginaba que por fin dejaba atrás el análisis de la obra crítica, esa voluntad de separar, de distinguir, de abstraer, de fragmentar el hombre. Sólo como un dardo dirigido contra esta autonomía de las diferentes esferas de acción propias de la cultura, tiene sentido profundo la otra tesis de El tema de nuestro tiempo, el perspectivismo. Sólo a través de este concepto tiene sentido la noción de individuo circunstancial que Ortega ha querido dejarnos como alternativa al sujeto trascendental.

Creo que con ello estamos llegando a la clave de la liberación de Kant que Ortega pretendió. Sin ninguna duda, el constructivismo de la subjetividad trascendental había sido reconocido por Ortega como el centro del activismo idealista. Lo propio de ese constructivismo era su vértebra universal. En cierto modo, Kant había jugado con las categorías de arquetipo y ectipo y había hecho de ellas la clave de todas sus metáforas. Por mucho que el hombre no tuviese ningún intelecto arquetipo, sí tenía un intelecto derivado. Aquí, como siempre, la secularización mantenía de la teología mucho más de lo que dejaba. Pues, se mire como se mire, el intelecto originario se mantenía estructuralmente en el derivado no sólo por su unidad, sino también por su universalidad. El segundo era la copia del primero en el espejo del espacio y del tiempo, pero no era menos copia única. A través de ese intelecto sensible, no menos averroísta que el agente, no se veía el paisaje de la cosa en sí, pero se contemplaba al menos el único paisaje del mundo fenoménico. Frente a esta erección de un Dios sensible, de un Logos en todo igual al Padre, y de un mundo humano reflejo del inhumano ser en sí, Ortega levanta su desconfianza radical: «Ese paisaje arquetipo no existe ni puede existir. La realidad cósmica es tal, que sólo puede ser vista bajo una determinada perspectiva. La perspectiva es uno de los componentes de la realidad. Lejos de ser su deformación, es su organización. Una realidad que vista desde cualquier punto resultase siempre idéntica es un concepto absurdo» (III, 199).

$\mathrm{El}$ intelecto arquetipo no se refleja en un intelecto ectipo o sujeto trascendental. La única ruptura con aquel intelecto es la que sólo acepta el entendimiento de los individuos. La realidad no se organiza desde perspectivas universales, categorías o conceptos puros, propios de un sujeto estructuralmente único, sino desde perspectivas individuales. No Kant, sino Leibniz: ésa es la cuestión ${ }^{24}$. No un sujeto trascendental que es un Dios inmanente, espacio-

${ }^{24}$ En un momento muy cercano al que estamos considerando, Ortega dice: «Toda mi devoción y gratitud a Marburg están inexorablemente compensadas por los esfuerzos que he tenido que hacer para perforarlo y salir de su estrechez hacia alta mar» (III, 433). El texto es claramente nietzscheano. En el artículo donde escribe esto, de 7 de junio de 1925, Ortega se lo dedica a Leib- 
temporal, reflejo de un intelecto originario, sino sujetos monadológicos cada uno de los cuales refracta a su manera una mirada sobre el cosmos que sólo la mente omnipotente que estuviera por encima de todos ellos podría unificar. Spinoza, el héroe filosófico de Meditaciones del Quijote, era igualmente desprestigiado. La species aeternitatis ahora es el correlato de una ciencia de abstracciones, de un hipotético y abstracto sujeto trascendental. Ortega decía Spinoza, pero en cierto modo quería decir Kant. En esto se parecía a Jacobi. Su tesis básica aspiraba a reducir la ontología de las ideas, dominante en aquel libro de 1914. Pues si existían las ideas, el sujeto trascendental tenía todavía algo que contemplar y conocer en su abstracción. Las ideas eran comunes a todos los sujetos, aquello que veían todas las subjetividades, el punto de convergencia de sus perspectivas. Ahora nada de eso existía, sino un mero universo en el que los seres humanos de carne y hueso vivían entregados a su individualidad radical. Una perspectiva abstracta era un verdadero oximoron. Ortega sabía demasiado bien que ese sujeto abstracto era necesario «para ciertos menesteres del conocimiento». Pero la ciencia no tenía una afinidad especial con lo real. De nuevo, la pluralidad de las esferas de acción coincidía también con la base teórica del perspectivismo.

El último capítulo de El tema de nuestro tiempo situaba al individuo en el centro de todas los cruces de las esferas de acción. Todas ellas eran perspectivas, desde luego, pero su único punto de síntesis real era el individuo, el único capaz de administrar su régimen de convergencia, de hostilidad, de complementariedad o de incompatibilidad. En lugar de ser el estorbo a la razón, el individuo era el único punto en que podía encarnarse una síntesis, pero ahora una vital y personal, no una verdad en sentido clásico, como síntesis de los diferentes predicados de la tradición filosófica. Eso era lo inaceptable del nekoantismo y de Kant: su noción de sistema, tan alabado en $1914{ }^{25}$. Puesto que estos predicados no tenían una relación lógica entre sí, puesto que las esferas de acción eran puntos de vista, perspectivas, su uni-

niz. Su alabanza se reduce a una loa del polimorfismo de su alma. «No ha existido en la especie humana alma más capaz y multiforme» (p. 434). Sobre esta pluralidad supo hacer una metafísica. Éste será el modelo futuro de Ortega.

25 «Es extraño oír hablar todavía de la cultura con patéticos ademanes. Este patetismo cultural fue precisamente el gran error de Alemania. [...] Toda esa insistencia sobre la unidad de la cultura pertenece a las pequeñas filosofías provincianas que en aquella época, y como simpática corrección del tosco positivismo, pulularon en Alemania y se vertieron por el resto de Europa. Todas ellas eran y se llamaban filosofía de la cultura, no filosofías de lo real. Son síntesis urgentes, arbitrarias, de una convencional estructura, sórdidas utopías en que se confunde la sinuosa y espléndida realidad con los míseros esquemas del llamado idealismo. A esta fauna filosófica pertenece la filosofía neo-hegeliana de Croce, la neofichtiana de Rickert y la neokantiana de mis maestros marburgueses. El neo prefijado a muchas de ellas anuncia su arcaísmo. Son trajes de viejos sistemas arreglados para otros cuerpos. En su hora tuvieron sentido, porque la generación anterior había perdido por completo la técnica de la filosofía y era menester reaprenderla. Pero, a la vez, se revela en ellas la incapacidad de construir originalmente la nueva síntesis de la vida» (III, 253). No estoy seguro, a tenor de lo que dice luego Ortega, que viera completamente claro en todo este asunto. 
dad sólo podía ser vital. La única verdad era la construcción artística de la vida como reunión de esferas de acción y de perspectivas. Goethe debía ser de nuevo pensado. Lo decisivo era encontrar el nuevo cemento de todas las esferas. A Ortega, como a Weber, le resultó claro en 1923 que ese cemento no era lógico ni sistemático. Sólo podía ser vital. Para nosotros, sin embargo, lo decisivo es comprender lo que esto quería decir.

El individuo era una realidad vital, histórica y perspectivista. La razón era la potencia que siempre había unido los diferentes ámbitos de la cultura, la potencia sistemática. Que la razón fuera vital significaba que esa potencia de síntesis tenía que darse y ejercerse en un aquí y ahora individual, con una fuerza creativa circunstancial. No debemos desechar el pensamiento de Ortega, según el cual esta potencia sintética se debía lograr desde una «profunda fidelidad a nuestro organismo» (III, 202). Freud hubiera aplaudido aquí ${ }^{26}$. Pero pronto hubiera visto una desagradable y limitada abstracción. Una vez más, creo que sin una economía de los deseos, no cabe pensar la manera en que las diferentes esferas de cultura pueden penetrar en nuestra personalidad. Quizás Ortega deseaba decir algo parecido. Que no es posible una administración genuina de los deseos - la clave de la razón vital - sin una vinculación a las instituciones del presente, esta tesis quizás pueda ser una buena forma de darle sentido a la condición circunstancial del ser humano, en la que Ortega insiste. De aquí se derivaba ese contacto de la cultura con las energías vitales, capaz de garantizar su creatividad y de impedir su anquilosamiento. De esa manera, la cultura no escapaba al horizonte del mundo de la vida de un individuo, tesis que Ortega casi está a punto de establecer. Como está a punto de anticiparse a este mundo de la razón husserliano, en tanto reunión intersubjetiva de las mónadas racionales en la mente de Dios, que sería el símbolo del torrente vital que en todas las vidas humanas se refracta (III, 202-3).

Ortega así tiene sentido. Sin ninguna duda, muchas consecuencias se seguirían de esta reducción de la razón pura a razón vital. Cualquiera que lea los dos apéndices que lleva El tema de nuestro tiempo verá que dos de ellas son muy relevantes: primera, el final de una razón carismática capaz de fundar almas ilusionadas; segunda, la imposibilidad de fundar revoluciones por una razón que ha perdido su carisma. A su manera, Ortega ve la revolución como el efecto directo de una razón pura y carismática, capaz de fundar todas las conexiones sistemáticas en la potencia de la coherencia lógica y de la ciencia. De lo buscado en 1914 ahora se despedía. La tercera consecuencia apunta a una crítica de la razón utópica y la necesidad de enfrentarse a lo

\footnotetext{
26 «La experiencia enseña, dice Freud, que para la mayoría de los hombres existe una frontera, más allá de la cual no puede seguir su constitución las exigencias culturales. Todos aquellos que quieren ser más nobles de lo que su constitución les permite sucumben a la neurosis. Se encontrarán mejores si les hubiera sido posible ser peores» («Moral sexual cultural y nerviosidad moderna», en Obras Completas, vol. IV, p. 1245.
} 
real en su concreción circunstancial - «a la faena que nos propone el destino», dice Ortega (III, 203) casi en lenguaje de Weber- y no a lo ideal en la perfección de su diseño abstracto. De hecho, la sistemática pura de la razón parte de considerar las esferas de acción como otras tantas dimensiones utópicas (III, 238). De ahí que su síntesis fuera considerada como a priori, cuando aquella que se da en el individuo sólo puede ser a posteriori y circunstancial. La cuarta, la reivindicación de la finitud (III, 242-2), sin la que la síntesis de las esferas es inviable pues, volcadas sobre su dimensión de infinitud, no genera sino una voluntad de especialización que reseca el espíritu.

No es un azar que Ortega, como el pensamiento de Weber, tuviera siempre en el horizonte a Goethe. De entre todos los pensamientos, el más constante a lo largo de toda la trayectoria de Ortega ha sido el de renovar el clasicismo. Todas las consecuencias de la razón vital apuntaban al gran debate: ¿cuál era el futuro del clasicismo en un mundo dominado por el romanticismo? Ortega no se engañaba en este punto. «Hay evidentemente en esta propensión al finitismo una clara voluntad de limitación, pulcritud serena, de antipatía a los vagos superlativos, de antirromanticismo. El hombre griego, el "clásico", vivía también en un universo limitado. Toda la cultura griega palpita de horror al infinito y busca el metron, la mesura» (III, 242). Y, sin embargo, cuando alcanzó este programa con cierta conciencia, Ortega pudo decir por primera vez que sería superficial «creer que el alma humana se dirige hacia un nuevo clasicismo». Que el asunto no era fácil lo testimoniaba el fracaso de Goethe, un caso de frivolidad, de mera apuesta por el neoclasicismo.

\section{Kant desde dentro}

Hemos visto cómo Ortega ha salido de la jaula. Ahora debemos mostrar que tenía la llave dentro desde el principio. La tesis puede decir así: $E l$ tema de nuestro tiempo replantea los asuntos de Meditaciones del Quijote. Ésta es una cargante repetición, pero es también algo diferente. El libro de 1914 no era sino una forma de resolver el problema de la cultura con la vida. Como tal, tomaba partido por una opción. El argumento era sencillo: España está dominada por sus muertos. Sólo podrá despertar a la vida si alguien logra que la cultura objetiva europea dinamizara las fibras subjetivas del alma española. Para ello, esa cultura objetiva idealista y europea debe conectar con el momento en que el alma española vivió algo grande, con el momento Don Quijote. Ortega vio esta posibilidad de ser español y creativo desde la cultura europea cuando Marburgo le recordó El Escorial y el libro de Cohen le hizo ver que una interpretación europea del Quijote era necesaria. Pero Ortega partía en todo caso de la circunstancia propia, de la 
individualidad, de la historicidad española, de la primacía de la vida individual sobre las grandes categorías universales. Es muy curioso que en Las Atlántidas, texto tan cercano al Tema de nuestro tiempo y a su homenaje a Kant, después de hablar de los individuos históricos de Rickert, Ortega recuerde que en relación con los verdaderos sujetos históricos, perspectivas de la tierra plural, su libro de Meditaciones del Quijote insinuaba una tesis muy parecida ${ }^{27}$.

Con Meditaciones no sólo se estaba identificando este problema de la vida individual, histórica y circunstancial como el fundamental. También comprendemos que el problema del individuo no era algo ajeno al neokantismo. Ya lo hemos visto que no lo era en Rickert. Con todo ello, Ortega en 1914 era muy consciente de que la cultura tenía que ser fecundada por la vida individual históricamente condicionada y circunstancialmente determinada para no quedar anquilosada en sus productos objetivos ${ }^{28}$. Por eso, Ortega tenía razón al considerar de una manera muy clara que: «Desde 1914 (véase mis Meditaciones del Quijote) es la intuición del fenómeno "vida humana" base de todo mi pensamiento» (VIII, 273) ${ }^{29}$. El mismo relato, con todos los temas que Meditaciones del Quijote anticipa respecto a los problemas de la razón vital, se puede ver en la larga nota que Ortega inserta en el momento de su homenaje a Goethe que trata de la vida como cura $^{30}$. Pero aquí hay dos confesiones más precisas: la primera, previsible, que esa constelación de temas primitivos de Meditaciones cristalizó en El tema de nuestro tiempo; la segunda, más rara, nos informa que el asunto decisivo de la vida como futurición fue «inspirado por cierto en cuestiones muy remotas del problema vital al que yo lo aplicaba - suscitadas por la lógica de Cohen»- . Las claves sueltas sobre la vida en las Meditaciones son reorganizadas en el año en que se liberó de Kant. Pero, a su vez, entonces reconoce Ortega que la clave se la inspiró la lógica de Cohen. La salida de la prisión no fue sino el hallazgo de una llave que siempre había estado dentro.

¿Pero cuál era esta llave? La relación genuina entre el concepto y la intuición, entre la abstracción y la existencia. El propio neokantismo veía el individuo como un residuo resistente a toda reducción lógica. Cohen había dejado este punto de vista muy claro y sobre el individuo podía hacer pie la historia, la poesía, el arte, la religión, todas aquellas formas de aproximación que luego Ortega calificará de metafóricas, porque aspiran a presentar el fon-

\footnotetext{
27 III, 300 .

28 En la edición de Marías, de Meditaciones del Quijote, Madrid, Cátedra, 1984, pp. 68-70.

29 Sin duda, en este relato, Ortega pasa inmediatamente a decir que «entonces lo formulaba yo - con motivo de exponer durante varios cursos la Fenomenología de Husserl- corrigiendo de modo principal la descripción del fenómeno "consciencia de" que, como es sabido, constituye, a su vez, la base de su doctrina». Esta parte del relato podemos dejarla de lado aquí porque no es central al punto. Como veremos, no es falsa, sino que es complementaria de la opinión anterior.

30 Allí Ortega habla de vida como inseguridad, frente a la seguridad de la cultura, del perspectivismo, de la circunstancia, de la aletheia (IV, 403, n).
} 
do secreto de las cosas, su yo y su vida ${ }^{31}$. La lógica del neokantismo, como la del kantismo, mostraba siempre sus propios límites en la existencia de la individualidad dada a la intuición. Por eso, el mismo punto donde Ortega divisaba el individuo afirmaba también la facticidad de la existencia, contraria enteramente a la epojé husserliana. De ahí la tendencia de Ortega a mostrar que su descubrimiento de la vida en Meditaciones del Quijote también era ya su crítica avant la lêttre a la reducción fenomenológica de Husserl.

Salmerón, frente a Orringer y Silver, ha identificado las fuentes reales, las verdaderamente operativas en Ortega ${ }^{32}$. Desde luego, como hemos visto, la obra de Ortega mantiene una inclinación vitalista que se descubre por doquier y desde el principio. Goethe no es ajeno a eso. Si no, cómo sería posible aquel comentario a Navarro Ledesma, de 16 de mayo de 1905, en el que, tras valorar su libro sobre Cervantes, en tanto «visión de la vida, propia, super y peri-científica, como si dijéramos la visión orgánica, elaborada», acaba diciendo: «Lo de Goethe, de que sólo las obras de circunstancias (quiero decir interiores, del autor) son firmes, es el evangelio» ${ }^{33}$. No cabe duda de que el neokantismo siempre miró ese concepto con desconfianza sistemática, pero también reconoció su inevitable pertinencia. La filosofía de primeros de siglo, desde Rickert, Weber o Cohen, prefería hablar de ser y de él hicieron la categoría metafísica fundamental. Luego, Simmel y Dilthey, tras Nietzsche, hablarían de vida. En él colocaban las apelaciones kantianas a la cosa en sí, porque en el fondo el ser era la exigencia y el reto de sentido en que consiste la vida humana. Todos ellos partieron de las distancias entre el ser/vida y el sentido/forma. Justo porque el ser o la vida eran ajenos a todo sentido humano - es la tesis de Ortega en Meditaciones del Quijote-, éste tenía que apresar el ser y expresarlo desde distintas perspectivas. Pero realmente, cuando todas las mediaciones lógicas llegaban a su límite, siempre volvía a alzarse la intuición con el ser y la vida, insobornables e irreductibles. Sin embargo, el ser como cosa en sí del inicio de la filosofía no era el mismo ser vivo que se mostraba como fortín ante el asalto de la lógica y de las mediaciones filosóficas, allí, en la intuición a la que debían referirse todos los conceptos. El primer ser era universal, el fondo inexcrutable de realidad. El segundo era el ser individual, existencial, circunstancial, no menos inaprensible desde la mera lógica. A ese ser se refiere la Logik der reinen Erketnnis de Cohen ${ }^{34}$. Así que Ortega, una vez más, dice la pura verdad cuando recuerda: el problema de la vida se lo sugirió la lectura del libro de Cohen sobre la lógica. Salmerón ha tenido la delicadeza de buscar las páginas.

\footnotetext{
${ }^{31}$ Salmerón, Las Mocedades de Ortega y Gasset, México, El Colegio de México, 1959, p. 113.

32 Para desarrollar estas ideas cf. mi introducción a las Meditaciones del Quijote, que preparo para Biblioteca Nueva.

${ }^{33}$ José Ortega y Gasset, Cartas de un joven español, Marid, El Arquero, 1991, pp. 604-605.

${ }^{34}$ Salmerón da las páginas, cf. op. cit., p f., p. 113, donde cita las pp. 347 y 348 de la cuarta edición alemana de Cohen de Logik der reinen Erkenntnis.
} 
Ortega se sentía inclinado a pensar el ser en términos de vida, como Simmel. Pero también, y desde la Crítica del discernimiento, el propio neokantismo había hablado de la existencia real del individuo a-lógico como vida. Este hecho fortaleció la tendencia de Ortega a situar la vida en el centro de su metafísica, tanto como concretó su aproximación a la vida a través de la estética, ese ámbito que los neokantianos situaban más allá de la lógica, en la intuición concreta, ámbito en el que la manifestación básica de la vida, el sentimiento, era imprescindible. Con estos antecedentes, podemos explicarnos que Ortega pronto llegase a la tesis de que «la vida de cada cosa es su ser». Si leemos este pasaje ${ }^{35}$, nos damos cuenta de que entra de lleno en la órbita del neokantismo. Pues en él dice Ortega que hay muchas realidades que únicamente son relaciones $o$, como hemos dicho nosotros, siguiendo a Cohen, mediaciones lógicas. Cuando éstas no funcionan más, cuando se acaban las mediaciones y las relaciones, cuando el reino de la naturaleza científica se detiene, si hay un residuo, entonces ahí se nos dará la cosa y con ella su ser inmediato, individual y vivo. Por eso su conclusión era que «por definición lo vital es lo concreto, lo incomparable, lo único. La vida es lo individual» ${ }^{36}$. Aquí aplaudiría Stirner tanto como Nietzsche, pero el propio Cohen sonreiría al recordar la página 347 de su Logik des reinen Erkenntnis, donde en el capítulo dedicado al «Problema de la vida» defendía justo esta posición ${ }^{37}$. Así que, después de todo, Kant siempre había tenido la puerta abierta: más allá de la lógica estaba la intuición y con ella la existencia, y la vida individual, y la circunstancia espacio-tiempo, y el realismo frente al que la lógica era sólo la organización de sus perspectivas.

A fin de cuentas, Kant también había afirmado siempre la superioridad de contenido de la intuición sobre el parcial concepto. Lo que para su sistema era un punto de llegada, más allá de todas las mediaciones conceptuales, bien podía ser para Ortega el punto de partida, más acá de las mediaciones conceptuales. Mas acá de la puerta y más allá de la puerta de la lógica siempre estaba la intuición como punto de partida. La diferencia era clara: el individuo vivo como ser existente era el final de las mediaciones del sistema kantiano. Para Ortega, elevado a ser libre, a vida libre, era el principio de un sistema futuro. Donde el neokantismo tenía su final, allí Ortega encontró un principio. Por eso sólo una aproximación coherente y continua a Kant desde dentro podía mostrar la salida de Kant. Cuando en 1929 Ortega volvió al asunto del centenario, reconoció que era un imposible lógico hablar de Kant desde dentro. Cuando se está dentro se vive, no se describe (IV, 48). Cuando se está fuera, entonces se puede hablar de una filosofía como parte de la razón vital de su autor. En este punto, Ortega se preguntó qué era lo vivo en Kant y se contestó diciendo que no era algo que estuviera ni dentro ni fuera,

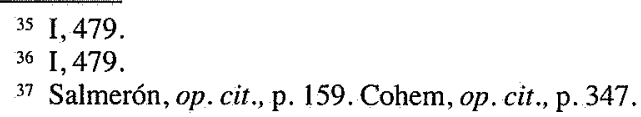


ni se podía vivir ni se podía meramente describir. Era algo que seguía siendo el enigma por el que podíamos salir de él, pero también la puerta por donde se podía entrar en él.

Eso que había en Kant y que no se resignaba a ser parte de la jirafa, sino que también se quedaba dentro de nosotros, como la puerta de acceso y de salida a la vez, era un problema vivo que también era el de Ortega. Kant había desplegado toda la potencia del logos, pero no había reducido el ser a logos. En los límites siempre estaba la existencia. El pensamiento ponía mucho en el ser de la cosa, pero el ser lo ponía la misma cosa ${ }^{38}$. Ese idealismo limitado por el ser, esa renuncia a una completa ocupación del ser por el pensar, era la clave de Kant. En cierto modo, se trataba de una voluntad de realidad, de una aceptación, a su manera, de la gracia de la donación. Cuando en 1929 Ortega se replanteó el problema de Kant, tuvo que ser justo y reconocer que, aunque lo había abandonado, de hecho también había seguido la propia invitación de Kant. «Que el ser no tenga sentido y no pueda significar nada si se abstrae de un sujeto cognoscente, y, por tanto, que el pensar intervenga en el ser de las cosas poniéndolo, no implica que los entes, que las cosas, al ser o no ser, se conviertan en pensamientos. [...] Kant protesta siempre que presume una interpretación idealista, es decir, subjetivista, de sus "objetos de la experiencia" porque, según su intención radical, la intervención del pensamiento y, por tanto, del sujeto en el ser de las cosas no traía consigo la absorción de las cosas en el pensamiento ni en el sujeto» (IV, 57). Así que la superación del idealismo fue posible porque Kant había llamado la atención sobre ello, recomendando un realismo empírico final. La raíz de este pensamiento, dijo entonces Ortega, coincide con «el tema de nuestro tiempo en filosofía».

Aunque odiaba a la mujer de Lot, Ortega ejerció con suficiencia y tino la mirada hacia el pasado. Es verdad que él, en contra de la leyenda, no contempló estatuas de sal. En realidad, el pasado estaba tan vivo como el presente. Todo se anima cuando Ortega mira hacia atrás, con el mismo azogue de la vida, y no se puede negar que hay un cierto espíritu de justicia en lo que Ortega quiere ver, una y otra vez, girando la mirada sobre su propio hombro. Kant había dado indicaciones permanentes para superar el idealismo impuesto en su nombre. La justicia hubiera sido total si, entonces, Ortega hubiera recordado que Cohen, al final de su libro de lógica, había defendido de forma radical que Kant era un consumado realista. El punto no está quizá aquí, sino en la reducción del sujeto trascendental a un sujeto que ya es un hombre que vive, un ente más que está abierto a lo objetivo (IV, 58). La razón práctica, como autodeterminación absoluta, pasaba entonces a ser la condición de la vida humana que ha de hacerse a sí misma absolutamente. Antes que Blumenberg discutiera las dificultades de auto-comprensión del

${ }^{38}$ Cf., para esto, mi viejo trabajo «La tesis de Kant sobre la noción de existencia», Revista Teorema, vol. X/1, 1980, pp. 55-85. 
hombre, y mostrara que quizás eran tales porque en el hombre no había nada que comprender, Ortega ha dicho con toda claridad - frente al verdadero idealismo de Husserl y Descartes - que «la vida del hombre es en su raíz ocuparse con las cosas del mundo, no consigo mismo» (IV, 58). La pregunta por el ser del hombre, a fin de cuentas, era un resumen de preguntas que no eran por el hombre. Situado en esta clave, Ortega demandaba un Kant futuro, no un Kant pasado. Es una lástima que Ortega, entonces, no hubiera reparado su metáfora inicial. Bajo la piel de la razón pura crecía una razón vital. El ligero paseante por el zoo, recién liberado, también era un poco Kant, por dentro. 